\title{
Elucidating Skills for Job Seekers: Insights and Critical Concerns from a Field Deployment in Switzerland
}

\author{
Mauro Cherubini \\ University of Lausanne, Department \\ of Information Systems \\ Switzerland \\ mauro.cherubini@unil.ch \\ Muhan Zhao \\ University of Michigan, EECS \\ USA \\ muhanz@umich.edu
}

\author{
Alex Jiahong Lu \\ University of Michigan, School of \\ Information \\ USA \\ alexjlu@umich.edu
}
Anandita Aggarwal
University of Michigan, School of Information
USA
aanandit@umich.edu

\author{
Joey Chiao-Yin Hsiao \\ University of Michigan, School of \\ Information \\ USA \\ jcyhsiao@umich.edu
}
Tawanna R. Dillahunt
University of Michigan, School of
Information
USA
tdillahu@umich.edu

\begin{abstract}
This article contributes results of a longitudinal field study of SkillsIdentifier, an employment tool originally designed and assessed in the United States (U.S.), to support "underrepresented" job seekers in identifying and articulating their employment skills. To understand whether the tool could support the needs of job seekers outside the U.S., we assessed it among 16 job seekers with limited education and language resources in Switzerland. While many of our results mirrored those of the U.S., we found that the tool was especially beneficial for non-French speaking immigrants who needed support describing their skills outside of their native language. We also found that listing skills like "active listening" without important context was insufficient and risked hiding key skills and meaning behind those skills to employers. Taking these factors into account, we illustrate the design implications of our findings and directions for practitioners who wish to design employment tools in support of job seekers, especially those who have traditionally been excluded from the labor market. We then provide insight into the potential for unintended consequences as a result of focusing solely on skills in a post-COVID labor market and contribute ways to mitigate them.
\end{abstract}

\section{CCS CONCEPTS}

- Human-centered computing $\rightarrow$ Empirical studies in HCI; User studies; - Social and professional topics $\rightarrow$ Employment issues.

\section{KEYWORDS}

Employment; labor market; underrepresented job seekers; soft skills

This work is licensed under a Creative Commons

Attribution-NonCommercial-ShareAlike International 4.0 License.

DIS '21, fune 28-fuly 2, 2021, Virtual Event, USA

(C) 2021 Copyright held by the owner/author(s).

ACM ISBN 978-1-4503-8476-6/21/06.

https://doi.org/10.1145/3461778.3462049
ACM Reference Format:

Mauro Cherubini, Alex Jiahong Lu, Joey Chiao-Yin Hsiao, Muhan Zhao, Anandita Aggarwal, and Tawanna R. Dillahunt. 2021. Elucidating Skills for Job Seekers: Insights and Critical Concerns from a Field Deployment in Switzerland. In Designing Interactive Systems Conference 2021 (DIS '21), June 28-July 2, 2021, Virtual Event, USA. ACM, New York, NY, USA, 17 pages. https://doi.org/10.1145/3461778.3462049

\section{INTRODUCTION}

Before the coronavirus (COVID-19) outbreak, the rate of employment had been increasing in most of the Organisation for Economic Co-operation and Development (OECD) countries and many had experienced growth in high-skilled versus low-skilled jobs [39]. Job seekers with less than a tertiary education and young people were experiencing difficulties transitioning to new high-skilled jobs and it was predicted that there would be additional risks of unemployment and underemployment for both men and women. This is despite the fact that unemployment risks for women in most countries is higher [39]. A failure to address these disparities, according to the OECD, would lead to deeper social divisions, and thus negative well-being, social cohesion, and overall growth. In addition, the effect of COVID-19 has exacerbated the difficulties faced by those who were previously unemployed. Past research suggests that crises exacerbate income inequality and those without university degrees (typically low-wage workers) far worse than those with university degrees (typically high-wage workers) [31]. In addition, the COVID-19 pandemic has adversely impacted employment among immigrant populations [4], who were already known to suffer from discrimination in hiring $[42,56]$. Thus, interventions to support these job seekers are needed, if not more urgently, at this time.

Historically, skills have been central to the discourse around capitalist production and the labor market. In today's workplace, skills are no longer limited to technical knowledge; instead, skills have become "almost anything that can be tested or ranked" in terms of their capacity to achieve desirable outcomes and profits for employers [24]. This way, skills are the critical factors in defining what ideal workers look like, how workers should understand and present themselves, and how workers should be assessed [51]. Researchers found in a U.S.-based deployment SkillsIdentifier, a digital intervention to help individuals identify and articulate their skill 
set, that the tool helped "underrepresented"1 job seekers improve their career identity and self-efficacy [17]. In this article, we refer to underrepresented job seekers as those who have traditionally been excluded from the labor market. With the disturbance on the labor market and the growing needs of job search worldwide brought about by the pandemic, we sought to understand the broader effectiveness and generalizability of SkillsIdentifier. Because the study was not longitudinal in nature, we first sought out to answer the following research question:

RQ1 - How do underrepresented job seekers integrate SkillsIdentifier into their long-term job-seeking practices?

Much of HCI-related research calls out the instability and precarity of work and the urgency to support job seekers who have traditionally been excluded from the labor market. HCI contributions thus far, include insights for designing employment tools to support these job seekers [18, 21, 26-28, 52], an understanding of the changing nature of work and the impact to job seekers [22, 29, 41, 47], and career mentoring in online communities [50], and fills an urgent gap.

Before the COVID-19 pandemic, U.S. statistics showed that a significant segment of unemployed people included those without a college degree [8], people with disabilities [9], racial and ethnic minorities [6], and women [7]. However, this past work has left a gap in terms of geography-much of this past work was conducted in the U.S. and as stated earlier, these inequities exist worldwide. Therefore, we aimed to fill this gap and extend this past work to answer our second research question:

RQ2 - How can SkillsIdentifier be improved to support the needs of job seekers more broadly (e.g., outside of the U.S.)?

Over a period of eight weeks, we iteratively developed SkillsIdentifier for our French-speaking context. Upon reaching a stable design, we assessed the tool via a longitudinal field study with 16 job seekers in Switzerland who consisted primarily immigrants and women. While many of our results mirrored those of the original study, further analysis of our interview data suggests that SkillsIdentifier helped job seekers, particularly non-French speaking immigrants describe and list their skills. We also found that for the tool to be most effective, listing skills alone is insufficient. Skills require context and most skills provided by the tool were basic skills stemming from an old database provided by the U.S. Bureau of Labor Statistics. Thus, it was unclear for job seekers how to highlight certain skills in their resumes without having more context to clarify meaning for basic skills. Along similar lines, reducing people to single skills like "active listening" can remove context and risks hiding meaning to employers. Taken together, we contribute the following to $\mathrm{HCI}$ and adjacent fields:

- Empirical results of a longitudinal field study with underrepresented job seekers in a Swiss context. Our results help to identify job seekers' perceived benefits and uncover concerns about using digital tools to identify their skills, career identity, and self-efficacy.

\footnotetext{
${ }^{1}$ The article refers to "underrepresented" job seekers (many of whom are racial and ethnic minorities who lack access to those social networks that are beneficial to employment) as job seekers who are underrepresented in the job market based on the educational and employment disparities that they face [17].
}

- Concrete design considerations to better support job seekers' skill elicitation and development in the processes of job search and career development.

- Ethical considerations of the unintended consequences of emphasizing skills in a post-COVID labor market and a critical discussion about the growing power asymmetry between job seekers and employers (especially given the rise of AIpowered hiring technologies).

\section{RELATED WORK}

\subsection{Characterizing Workforce Skills}

The skills essential to effective workplace performance is a question that has been asked many times throughout the 20th and 21st centuries [30]. Attempts to characterize workforce skills stress the importance of specific job characteristics (e.g., ability to code in Python) or human characteristics (e.g., reasoning ability), and there is variation in the way people communicate such skills [30]. Descriptions such as listening or problem solving skills are quite general whereas decorating spaces for kids ages 3-5 are quite specific. In other words, some skill descriptions lack specific context and identifying and communicating this information has been a long-standing challenge [30]. Rapid changes in job content require broader and more generic skills and these skills might be similar across higher and lower-skill jobs. Understanding how and when to convey such skills is an open question and some people struggle to assess their skills without having an education or prior work experiences [37]. Thus, an open opportunity exists for technology to provide this type of support, which this work aims to explore.

Hard skills and soft skills are the two types of skills that have been traditionally included on resumes. Hard skills are often described as objective-these are skills that can be taught and are quantifiable. However, such objective measures only access a limited number of abilities (e.g., they do not assess soft skills) and do not address self-perceptions [37]. However, most research is based on objective measures of ability assessment, which are often obtained by asking individuals for their skills directly [37]. While there are many definitions for the term soft skills, the common thread in all definitions is that these skills have a subjective orientation and thus can not easily be measured, observed or quantified; they are difficult to teach; and they are necessary to increase an organization's productivity [38]. Examples of soft skills include interpersonal and leadership skills, emotional intelligence, communication, time management and business etiquette [13] and allow for people to effectively manage life's challenges [53]. Although many of today's graduates focus on their hard skills or demonstrable skills on resumes, they put themselves at risk of successfully finding employment [1] because employers' demands for soft skills are increasing [25]. In fact soft skills often replace employers' requests for technical skills [ibid.]. Thus, educational institutions should facilitate soft skill formation among graduates by making them more explicit learning outcomes [36]. Given that not all job seekers have access to education, there are opportunities for digital employment tools to provide this type of support.

\subsection{Skills, the Labor Market, and Employment}

Throughout the history of capitalist production and in today's capitalist labor market, an individual's value is dependent on their 
skills. According to Urciuoli, the notion of skills has shifted from "a specific manual or machine operation" to "any practice, form of knowledge, or way of being constituting productive labor" [51, p.212]. In other words, skills have been reimagined as commodities. In this way, skills can be measured by their capacity to contribute to monetary outcome. Gershon contends that the job market has moved to a "self-as-business" paradigm, which requires job seekers to present themselves as "bundles of skills" that can be used to address organizations' issues and needs [24]. The European Union has rolled out the skill-based European Skills Card as the "quantifications or skill outcomes of learning and working periods" [46, p.107] and "opens up new avenues for validating skills" [12]. Abilities like "speaking French" and "actively listening in the meetings" are categorized under the umbrella of skills, so that they can be "objectively" measured, evaluated, and compared with other individuals' abilities by employers. This "self-as-business" paradigm, as a result, requires job seekers' to put forth effort in terms of how they manage their self-presentation in the job search process. In particular, Gershon highlights the challenge of accurately representing their situated experiences with tokenized skills in the job application process [24].

Past work in HCI has engaged with job seekers in acquiring technical skills [48] and identifying necessary skills to reach their dream jobs [20,34]. In particular, Suzuki et al. designed a microinternship platform-Atelier-to help novice crowd workers develop the skills needed to deliver expert crowdsourcing tasks [48]. The platform paired novices and crowd experts to collaboratively break down a project into detailed milestones. In Dillahunt and Lu's work, they considered skills as the "stepping stone" and building blocks to help underrepresented job seekers to move to their dream jobs $[20,34]$. In particular, they implemented a system, DreamGigs, to help job seekers identify the skills that job seekers did not possess for their dream jobs and a path for job seekers to develop those skills. While this past work focused on new skill acquisition and development, limited work has supported underrepresented job seekers' self-presentation or helped them to identity their skills based on their work experience. This current study aims to address this gap (RQ1) and as a result of exploring this question outside of the U.S., aid in our understanding of how to support the needs of job seekers more broadly (RQ2).

\subsection{The Labor Market in Switzerland and the Importance of Skill Transfer}

Throughout the last few years, the Swiss job market has undergone important changes. Country-wise, the majority of workers in Switzerland were employed in the service sector (71\%), a quarter of workers were in industry and trade $(25 \%)$ and about $4 \%$ in agriculture [15]. While the unemployment rate is very low in comparison to the rest of Europe, the unemployment rate has grown considerably in the past few years of this study being conducted and even larger throughout the COVID-19 pandemic. For context, the country is known for its mechanical watchmaking, which is of high quality. The watchmaking industry represents the third largest Swiss export after chemicals and machinery. However, the country experienced dramatic job market shifts starting in 2016 due to the advent of smartwatches. The retail segments moved online and were attracted by new manufacturers such as Apple, Samsung, and Fossil that could offer better integration with mobile technology. As a result, the manufacturing industry experienced export reduction and had removed a significant portion of the workforce. ${ }^{2}$ Switzerland is also one of the EU country with the highest share of immigrants. Recent research has revealed that immigrants often face ethnic discrimination in the hiring process [56], and they might require more support to find a job than Swiss nationals.

Thus, many job seekers seek to understand the skills they possess that could transfer to new industries and what reskilling may be required. To support job seekers, the country requires them to register to job-placement offices of the canton of residence and complete mandatory training. They are assigned a case worker to meet with once a month who in turn defines additional training courses to complement their current skills. Given the focus on skills in this context and the need for job seekers to find complementary skills to transition to new jobs, we sought to understand whether the SkillsIdentifier tool, as described in past work [19] might generalize in the Swiss context. Given the research described in the previous section and the timing of our research, we also sought to investigate what skills mean in a post-COVID world.

\section{SKILLSIDENTIFIER: DESIGN AND IMPLEMENTATION}

Figures 1 and 2 show the SkillsIdentifier user interface and user flow used in our study. ${ }^{3}$ For context, SkillsIdentifier was designed as a stand-alone tool to highlight how a job seeker's current set of skills overlap with those needed for their targeted job. As noted earlier, employers have evaluated job seekers' capacities and competencies by measuring their "bundle of skills" [24]. Meanwhile, a growing number of data-driven systems have been designed to assist employers, job seekers, and workforce development professionals to quantify skills needed to qualify for a particular position. Thus, the design of SkillsIdentifier relied on one of the most popular employment databases for job analysis-the U.S. Department of Labor's O*NET database [49]. The O*NET database outlined a number of standardized competencies (i.e., skills necessary for each job position). While $\mathrm{O}^{*} \mathrm{NET}$ provided a general explanation for each key skill, it did not offer nuanced explanations about why the selected skills were necessary for each position. Therefore, while SkillsIdentifier provided a simple and straightforward solution for job seekers to identify their skillset in their resumes and interviews [19] it did not provide these nuanced explanations. In the following subsections, we describe how we developed SkillsIdentifier and its user flow.

\subsection{SkillsIdentifier Development}

Our approach was very similar to that described in the U.S.-based SkillsIdentifier study [17]. We built on the prototype developed in the prior study, which was available as open-source software on Github ${ }^{4}$. As described in the original study, we also followed a three-phased iterative design process. We created a proof-ofconcept version of the tool, iterated over our design, and received

\footnotetext{
${ }^{2}$ See https://www.bbc.com/news/business-46822929, last retrieved February 2021.

${ }^{3} \mathrm{~A}$ translated version of this figure is available at https://osf.io/5xs6t/,

${ }^{4}$ https://github.com/UMICTResearch/SkillsIdentifier-MVP
} 


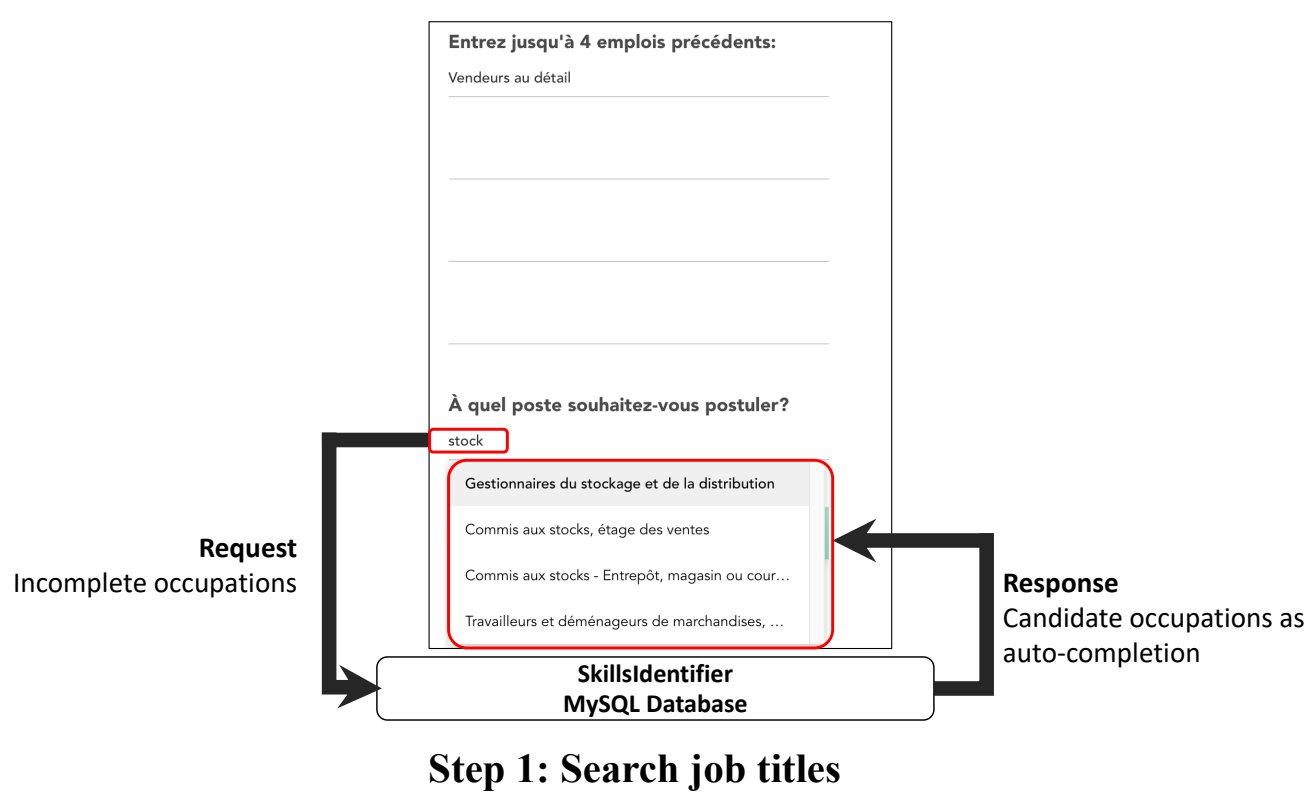

Figure 1: SkillsIdentifier user flow Step 1: This figure shows SkillsIdentifier's homepage. Job seekers enter incomplete occupations on SkillsIdentifier's homepage. SkillsIdentifier then queries the incomplete occupations from the MySQL database and returns a list of candidate occupations as auto-completion.

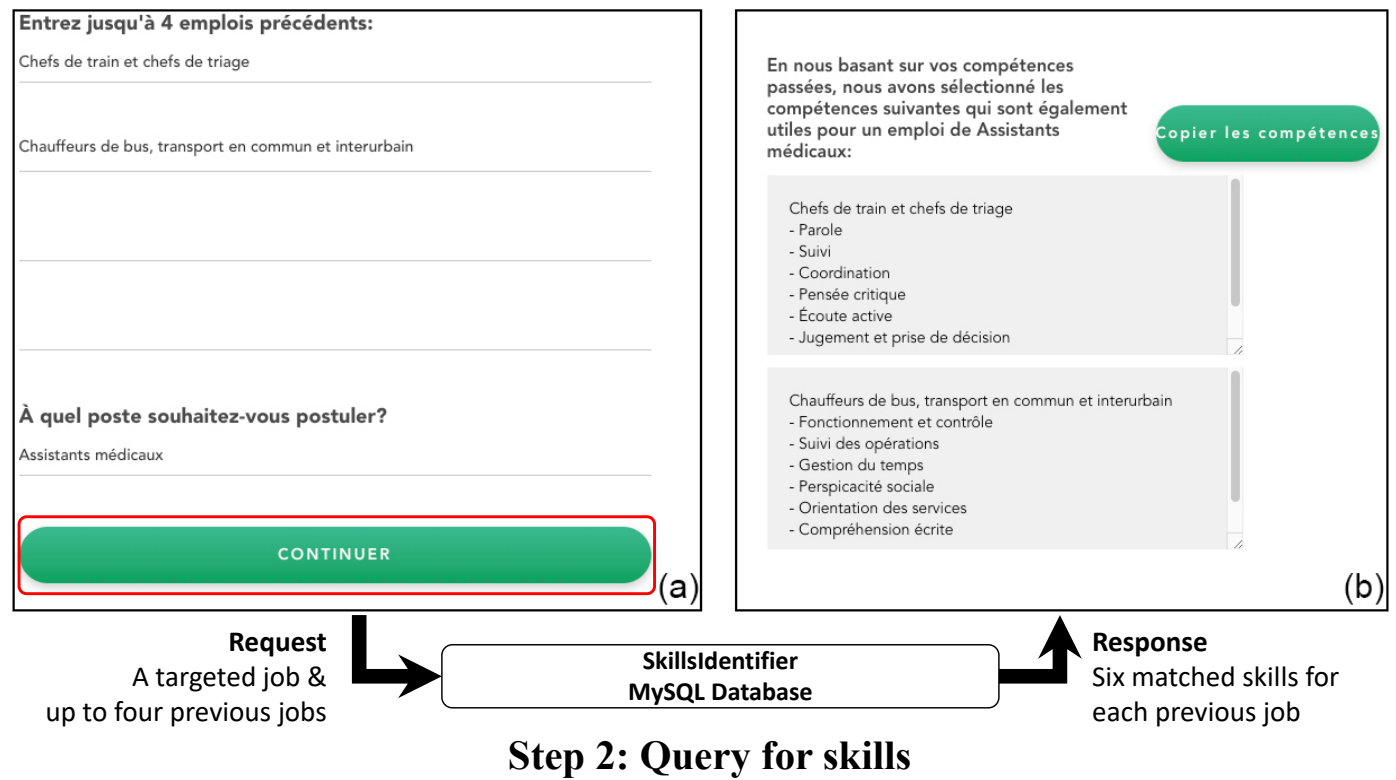

Figure 2: SkillsIdentifier user flow Step 2: (a) This figure shows SkillsIdentifier's homepage. Job seekers can enter up to four of their previous jobs and their targeted job (i.e., the job they wish to apply) on the home page. After they enter their jobs, they can press the Continue button to move on to the output page. (b) This figure shows SkillsIdentifier's output page. SkillsIdentifier outputs skills based on their past job experience and their targeted job. For a translated version of (a), please refer to Figure 7 a. The block of text at the top of (b) reads: "Following your past competencies, we have selected the following competencies that are also relevant for a post of Medical Assistant."

internal feedback. We incorporated a minimalist design and used the Ionic Framework ${ }^{5}$ for client-side implementation of the tool.

\footnotetext{
${ }^{5}$ See https://ionicframework.com/, last retrieved January 2021.
}

This framework is agnostic to operating and hardware systems and runs in a browser. Thus, it could run on a Windows desktop machine or on an Android or iOS device. This was particularly important in past work for job seekers who might have limited 
access to technology or who relied on shared devices [16]. We also did not require users to authenticate when accessing the tool, which was recommended in past work.

We then constructed our own MySQL database for SkillsIdentifier to store all the occupations and competencies data, specifically by utilizing the $\mathrm{O}^{*} \mathrm{NET}$ database [49]. The original $\mathrm{O}^{*} \mathrm{NET}$ dataset contained $\sim 1 \mathrm{~K}$ distinct occupations and numerical scores that matched these to four groups of competencies: abilities (52 items), knowledge (33), skills (35), and workstyles (16). We translated all the occupations and competencies to French, since we were deploying the study to a French-speaking region. Both occupation and competency labels were translated by a professional language specialist and cross-checked by another language specialist. This database not only supports queries for skills, abilities, and knowledge and how they relate to jobs, but also enables auto-completion of job titles and skills associated with the jobs that have been entered. Building our own database significantly increased the speed of access and allowed for more customization. Other minor UI elements were translated using the same approach.

\subsection{SkillsIdentifier User Flow}

Figures 1 and 2 show the two steps required to use SkillsIdentifier. In Step 1, job seekers enter up to four of their previous jobs and the job that they wish to apply to (i.e., their targeted job). We implemented an auto-completion function so that job seekers could enter incomplete occupations and SkillsIdentifier could provide a list of candidate occupations by drawing from the MySQL database (see Figure 1).

In Step 2, job seekers press the Continue button after they enter their targeted and past jobs (Fig 2a). SkillsIdentifier then provides job seekers with the overlapping skills to highlight in the output page (Fig 2b). We decided to present the top six matching skills for each past job entered to provide users with sufficient choices to put forward for each past position. In the output page, we presented the user with a Copy button, which would enable job seekers to easily copy the skills into an editable version of their resume. We focused on a single competency for the tool to output-skills versus abilities, knowledge, and workstyles. Given the emphasis on skills in prior literature as we discussed in our related work (e.g., [17, 19, 24]), this was the most relevant set of information to present. We also felt that it was also the most relevant information users might have wanted to access. Later during the field study, we realized the other competencies could have also provided useful information to the users, as we discuss in Sec. 5.5. We discuss our research methodology next.

\section{METHOD}

For context, our study took place in the French-speaking regions of Switzerland, primarily in the Neuchâtel and Vaud cantons ${ }^{6}$ from June to July 2020. We chose this particular context to deploy our study because of the similarities with the job-market dynamics of the location where SkillsIdentifier was originally tested. ${ }^{7}$ As the official language of these cantons is French, we designed all study

\footnotetext{
${ }^{6}$ Cantons are semi-sovereign states.

${ }^{7}$ The US Midwest region is known for it's strong automotive industry, which, like the Swiss watchmaking industry, was transformed by the introduction of automation.
}

materials and collected data in French. We conducted a 3-week field study with underrepresented job seekers. The field study consisted of three parts: an onboarding session, the 3-week tool deployment, and a final interview session. Both onboarding and final interview sessions included semi-structured interviews (see Figure 3). Due to the COVID-19 pandemic, all interactions with the participants happened remotely via Zoom. Participants were compensated for their participation in the study with 50 Swiss Francs ( 54 USD). The study was reviewed and approved by our university's IRB committee.

\subsection{Participants Recruitment}

We employed both offline and online recruitment methods and used the following eligibility requirements for our recruitment: 1) participants needed to have been actively seeking employment for the last six months; 2) have either a digital or physical copy of their resume; and 3) internet access. We established the first criteria to ensure recruitment of participants who might have needed extra employment support. ${ }^{8}$ The second criteria was established to observe weather (and how) participants were already listing their soft skills in their resumes. Finally, the third condition was necessary to ensure participants could access SkillsIdentifier during the study. We established a connection with the regional employment center (Office régional de placement, or ORP) to aid in our recruitment efforts. After signing a data protection agreement, the ORP granted us access to a list of 3200 active job seekers who had opted-in to be contacted for surveys and other research. Out of this initial list, we further filtered to those who had been enrolled to the ORP for at least six months and who did not hold advanced educational degrees to more closely match those of the job seekers from prior studies. After applying the filters we were left with approximately 1700 job seekers who matched the criteria. We randomized the list of candidates and began contacting them sequentially. We contacted candidates matching our criteria over the phone to schedule the first meeting. We sent candidates who were available and who agreed to participate an email invitation that included an informed consent for explaining the different phases of the study, and the conditions for participating. We contacted a total of 40 candidates from the original list. Of these, 12 participants refused for various reasons (e.g., lack of time, low interest), while $11 \mathrm{did}$ not answer our phone calls or their contact information had changed. A total of 16 participants took part on the field trial. We stopped enrolling new participants at the point of data saturation or when no new data insights were being collected about the tool and participants' experiences using it.

\subsection{Participants and Data Overview}

Table 1 shows our participants' background information. Given that the unemployment rate for women was higher in the country where we conducted the study [32], we over sampled for women participants. At the end of our recruitment cycle, we had a total of 11 women and 5 male participants. Most participants were

Automation there similarly led to the replacement of assembly-line jobs and subsequently the loss of tens of thousands of jobs. Many plants moved outside of the US and workers were left to find new jobs.

${ }^{8}$ According to recent statistics the average unemployment spells duration is around 6 months [5]. 


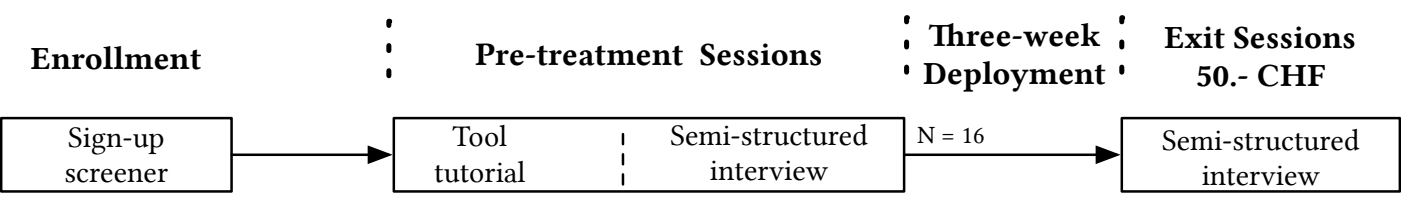

Figure 3: The field study consisted of three parts: an onboarding session, the 3-week tool deployment, and a final interview session. Given the exchange rate of 1.08, the incentive corresponded to $\sim 54$ U.S. Dollars.

middle-aged $($ mean $=40.1, \mathrm{SD}=11.8)$ and the median annual income of participants for the previous year was in the range 48 '000$84^{\prime} 000$ CHF. ${ }^{9}$ While only 1 participant did not finish high school, we recruited 5 participants who had a high-school degree, 5 who had an associate's degree, and 3 who had a bachelor's degree. The two remaining participants had accrued some college credit in their past but they did not complete the courses to get a degree. Ten of the sixteen $(62.5 \%)$ participants were immigrants. While seven were non-native French speakers, all except two spoke French at a conversational level. We conducted interviews in English for these two participants and provided English translations of the study materials (e.g., Skills Identifier UI labels, forms).

\subsection{Onboarding session}

Our pre-treatment sessions lasted a total of 45-60 minutes each. During the session, we conducted a semi-structured interview, and provided a tutorial of SkillsIdentifier. Following the original study, participants described their employment status, job search strategies and recent job search experience. To understand their career narrative and identity $[40,44]$ we asked them to describe their dream job. Then, we asked additional questions about their feelings about their job search and outcomes and their experience using digital tools in their job search. Next, we asked participants to show the resume and the cover letter they most recently used. Specifically, we wanted to see whether and how they presented themselves and whether they listed their skills for that.

After this initial phase, we showed our participants how to use SkillsIdentifier. First, to help describe the tool, we showed participants the storyboards that had been made openly-available from the original study [19]. ${ }^{10}$ Next, we demonstrated our prototype to participants to show them how to use the tool. Participants then followed instructions to enter their previous jobs and the position they were seeking (see Figure 2a). The output of the tool included the set of skills that intersected with their past jobs and the job they were seeking (see Figure $2 b$ ).

After job seekers went through the outputted list of skills, we conducted a brief interview to gather their overall thoughts about the tool. Sample interview questions included: "What are your thoughts about the skills that were identified based on your past job(s)?” and "How would job seekers like you benefit from a tool like SkillsIdentifier?" We also asked about their past experience articulating skills in their job search.

\footnotetext{
${ }^{9}$ Swiss Francs. At the time the study was conducted, the exchange rate with U.S. Dollar was $\sim 1.08$.

${ }^{10}$ The storyboards used in this study are available at https://osf.io/5xs6t/.
}

\subsection{Three-Week Deployment}

Each month, the job seekers in the region where we deployed the study are required to submit $\sim 10$ applications to open positions. Therefore we estimated three weeks to be a sufficient amount of time for our participants to seek the type of support provided by SkillsIdentifier. This longitudinal trial was designed to give the opportunity for participants to try the software in their own context and in their own time, without the pressure of an experimenter observing them. We tasked our participants to think about whether the tool could support their job search activities and if it was relevant. We asked participants to navigate to the website to generate a list of skills, and keep a copy of the output and their search criteria (i.e., the target occupation). We clarified that they were free to use the tool, or not, depending on whether they felt the need for it. We did so to gauge how often job seekers would need SkillsIdentifier in a real-world setting.

\subsection{Final interview session}

The goal of the final interview session was to collect feedback on the tool, and observations on whether the software was used in real job-seeking tasks. We asked participants whether they did or did not use the tool and why. If they used the tool, we asked them to show what they did with it. If using the tool led to them making changes in their $\mathrm{CV}$, or their cover letter, we asked them to describe the changes and explain why they made them. More specifically, we asked them to comment on the list of skills that they obtained from the tool.

\subsection{Data Analysis}

Our dataset included 32 audio recordings of semi-structured interviews (i.e., 16 participants $\times 2$ interview sessions), which were professionally transcribed. The transcripts were not translated. The dataset was analyzed in French to preserve the richness and nuances expressed in the original language. ${ }^{11}$ The quotes that were selected for inclusion in the paper were translated in English. We also took observation notes which captured users' past jobs and the jobs that they were targeting. The total length of the interview recordings was 12 hours and 55 minutes (mean $27 \pm 10$ minutes).. The shortest interview was 18 minutes, and the longest was around an hour. ${ }^{12}$ Four recordings were corrupted and researchers relied exclusively on the notes that were taken during those sessions.

We analyzed the transcripts using content analysis. As this study was heavily inspired by the study of SkillsIdentifier in the US, we started with provisional coding [43, p. 144]. We requested and

\footnotetext{
${ }^{11}$ The interviews conducted in English were analyzed in English.

${ }^{12}$ The setup part of the interview, which included the signature of the consent form, and the salutations were removed from the recordings.
} 
Table 1: Participant demographics. Income = participants' annual household income in the past year. Origin: $S=S w i t z e r l a n d$, $I=$ Immigrant. ${ }^{*}=$ targeting a job that differed from past employment and required training/education.

\begin{tabular}{|c|c|c|c|c|c|c|c|c|}
\hline ID & Gender & Age & Origin & $\begin{array}{l}\text { Monthly Income } \\
\text { CHF }\end{array}$ & Education & & Target Job & Past Jobs \\
\hline 1 & $\mathrm{~F}$ & 29 & $\mathrm{~S}$ & $7000-12000$ & Associate Degree & & HR assistant & HR assistant ; Administrative assistant \\
\hline 2 & M & 22 & I & $0-4000$ & $\begin{array}{l}\text { High school graduate, } \\
\text { diploma or the equivalent }\end{array}$ & & Waiter & Waiter ; Skipper ; Delivery service \\
\hline 3 & $\mathrm{~F}$ & 52 & I & $0-4000$ & $\begin{array}{l}\text { High school graduate, } \\
\text { diploma or the equivalent }\end{array}$ & * & Nurse assistant & Babysitter ; Security agent ; Cleaning assistant \\
\hline 4 & $\mathrm{~F}$ & 37 & $\mathrm{I}$ & $4000-7000$ & Bachelor's degree & * & Police officer & Administrative assistant ; Receptionist \\
\hline 5 & M & 20 & $\mathrm{~S}$ & $4000-7000$ & Some college credit, no degree & & Programmer & Robotics Engineer ; Programmer \\
\hline 6 & $\mathrm{~F}$ & 50 & $\mathrm{~S}$ & $4000-7000$ & Associate degree & * & Fashion stylist & Sales Manager \\
\hline 7 & $\mathrm{~F}$ & 60 & I & $4000-7000$ & Associate degree & & Administrative Assistant & Administrative Assistant \\
\hline 8 & $\mathrm{~F}$ & 53 & $\mathrm{~S}$ & $7000-12000$ & Some high school level & & Administrative Assistant & Administrative Assistant \\
\hline 9 & M & 33 & $\mathrm{~S}$ & $7000-12000$ & $\begin{array}{l}\text { High school graduate, } \\
\text { diploma or the equivalent }\end{array}$ & * & Administrative Assistant & Paychecks Manager ; Control System manager \\
\hline 10 & $\mathrm{~F}$ & 47 & I & $4000-7000$ & $\begin{array}{l}\text { High school graduate, } \\
\text { diploma or the equivalent }\end{array}$ & * & Warehouse Clerk & Sales (Retail) \\
\hline 11 & M & 39 & $\mathrm{~S}$ & $4000-7000$ & Associate degree & & HR Manager & HR Manager \\
\hline 12 & $\mathrm{~F}$ & 38 & I & Prefer not to disclose & $\begin{array}{l}\text { High school graduate, } \\
\text { diploma or the equivalent }\end{array}$ & * & Assistant nurse & $\begin{array}{l}\text { Retail sales ; Nanny ; } \\
\text { Cleaner }\end{array}$ \\
\hline 13 & $\mathrm{~F}$ & 35 & $\mathrm{I}$ & $4000-7000$ & Bachelor's degree & * & IT Specialist & Sales (Retail) \\
\hline 14 & $\mathrm{~F}$ & 37 & I & Prefer not to disclose & Bachelor's degree & * & $\begin{array}{|ll|}\text { Special } & \text { Education } \\
\text { Teacher } & \\
\end{array}$ & $\begin{array}{l}\text { Teacher assistant ; } \\
\text { Personnel care helper }\end{array}$ \\
\hline 15 & $\mathrm{~F}$ & 34 & I & $4000-7000$ & Associate Degree & & Teacher & Sales (Retail) ; Teacher \\
\hline 16 & M & 56 & I & $4000-7000$ & $\begin{array}{l}\text { Some college credit, } \\
\text { no degree }\end{array}$ & * & Concierge & $\begin{array}{l}\text { Online sales ; Game manager ; } \\
\text { Administrative service director; Stock manager }\end{array}$ \\
\hline
\end{tabular}

received the US team's code book to start with an initial list of codes. Later we enriched the codebook to reflect the findings of the Swiss study.

In the analysis, we aimed to identify 1) how participant's perceived the tool and the tool's benefits, and 2) ways to improve the tool. We adapted initial coding [43] in the first-round analysis by reviewing the transcripts line-by-line. In the first-round analysis, we focused on coding participants' comments on SkillsIdentifier (e.g., SkillsIdentifier's immediate and potential long-term benefits), participants' thoughts about the presented skills, potential improvements to SkillsIdentifier, and opportunities to develop better employment tools for our population.

In the second-round analysis, we grouped the codes into categories. We leveraged the codes outlined by the authors of the prior study [17] to categorize our quotes. Some examples of categories included unrealized skills, soft skills, and self-efficacy. In the following rounds of analysis, we organized the quotes and categories iteratively to identify themes that were related to our research questions. Many emerging themes were similar to those of the original study and spoke to how participants benefited from SkillsIdentifier. These included Raising Skills Awareness, Inspiring Reflection and Career Identity, Fostering Self-efficacy, and Fostering Career Exploration. A new emerging theme included Future Design Opportunities, which included participants' thoughts on how SkillsIdentifier's design could be improved. We present these themes in each subsection of our results.

\section{RESULTS}

As stated earlier, a total of 16 participants took part in our study. During the three-week study, 13 out of the total 16 participants used the tool on their own and reviewed the suggested list of skills. Of these, three participants used the tool two or more times (P2, P8, and P13) and the remaining 10 participants used the tool only once. Of the 13 participants who used the tool during the deployment, 6 used the output generated by SkillsIdentifier to change their resume and/or their cover letter (P1, P3, P8, P10, P11, and P14), while the others used the tool but did not change their resume or cover letter (P2, P4, P9, P12, P13, and P15). The remaining three participants did not use the tool after the onboarding session (P5, P7, and P16). They reported different reasons for not doing so: P5 could not find useful skills in the list of suggestions during the onboarding session, P7 reported not having the need as he could not find positions to apply to during the period, and P16 did not know how to show skills in his resume. We will come back to this last point later. Note that Table 1 includes job seekers' target and past jobs. During the study, 9 participants were looking for jobs that differed from their past employment experiences as they required training/education. These participants are marked with an asterisk $\left(^{*}\right)$ in Table 1.

In the following subsections we address each of our research questions: RQ1 - "How do underrepresented job seekers integrate SkillsIdentifier into their long-term job-seeking practices?" and RQ2 - "How can SkillsIdentifier be improved to support the needs of job seekers more broadly (e.g., outside of the U.S.)?” We first present results that mirrored and extended the past study [17]. We refer to these as the baseline benefits of the tool and present new themes that did not appear in the prior study. The new themes were: Supporting Skill Appropriation and Adaptation and Supporting Vocabularies and Structure for fob Seekers in Need. We also identified two needs that SkillsIdentifier did not satisfy: Missing Context for Basic Skills, Lack of Guidance to Present Soft Skills. 


\subsection{Replication and Extension of Findings of the Previous Study}

SkillsIdentifier was initially tested in the U.S. through a series of contextual interviews with job seekers [17]. That initial study did not provide longitudinal access to the tool and focused exclusively on the U.S. job market. In the current study, SkillsIdentifier was tested in a non-U.S. context and access to the tool was provided to participants for several weeks. The original findings were also verified by our current study. Thus, we felt it important to report the relevant similarities between the two deployments to provide initial evidence of generalizability of the original results. In the following paragraphs, we present three benefits of SkillsIdentifier: Increasing skill awareness; Fostering self-reflection on career identity; and Inspiring career exploration. Although participants described similar benefits, we include examples that did not appear in the initial study [17], and that reveal additional facets of the same benefits, namely rethinking their competencies in unfamiliar positions, reflecting on the job families of their past employments, and identifying skills they would need to acquire.

5.1.1 Increasing Skill Awareness. SkillsIdentifier raised participants' skill awareness in five aspects. Most straightforwardly, participants were able to include skills in their job search materials. For skills that participants were aware of, SkillsIdentifier helped to highlight overlapping skills between similar jobs, identify transferable skills for dissimilar jobs, and articulate skills that were vague to them. For skills that participants were unaware of, SkillsIdentifier also helped to identify unrealized skills.

SkillsIdentifier allowed most participants $(\mathrm{N}=12)$ to learn about skills to include in their resumes, cover letters, and interviews. More than half of participants $(\mathrm{N}=11)$ reacted positively to the list of skills presented by the tool. They saw the immediate benefit of receiving suggestions about the key competencies for each occupation. By reviewing skills listed by SkillsIdentifier, participants' awareness of their own skills improved.

The tool allowed job seekers to see their skills and increased their awareness of their transferable skills, or how their skills could be used for different jobs. For example, P3, an immigrant who worked part time (at 60\%) and was looking for a full time position, entered babysitter, security agent, and cleaning assistant as her past jobs. She entered nurse assistant as her target job (Figure 4). By way of using the tool, she realized how active listening, a skill listed across her past jobs, was associated with her target job. Although P3 understood that the past babysitting job fostered active listening, she was not aware that this skill was also important for nursing. Helping job seekers understand common and transferable skills allowed space for them to rethink their competencies in seemingly unfamiliar positions.

Participants also benefited from SkillsIdentifier by learning how to articulate their skills. P6 worked as a sales manager for 20 years but decided to look for a position as a fashion stylist. She stated: "I have a hard time communicating my competencies in terms of skills" and commented that "this tool [SkillIdentifier] really gives a good idea of the keywords required to describe the competencies that I learned in my past jobs." As P6 suggested, job seekers often did not have the verbiage to describe the skills they had. Providing the appropriate language to describe these skills could help job

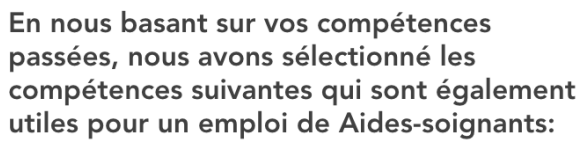

Nounous

- Parole

- Perspicacité sociale

- Écoute active

- Suivi

- Jugement et prise de décision

- Résolution de problèmes complexes

Les agents de sécurité

- Compréhension écrite

- Pensée critique

- Coordination

- Écriture

- Apprentissage actif

- Persuasion

Bonnes et femmes de ménage

- Orientation des services

- Gestion du temps

- Enseignement

- Analyse du contrôle de la qualité

- Gestion des Ressources en Personnel

- Stratégies d'apprentissage

Figure 4: Sample output of P3's query. P3 entered nurse assistant as her targeted job, and entered babysitter, security agent, and cleaning assistant as her past jobs. The block of text at the top of screenshot reads: "Following your past competencies, we have selected the following competencies that are also relevant for a post of Orderly".

seekers to better communicate and demonstrate their competencies in professional terms. We found skills articulation and identification support particularly useful for immigrants, as we detailed in Subsec. 5.3.

In addition to identifying skills in which job seekers were already aware, 5 participants (P1, P2, P3, P5, and P6) commented on how SkillsIdentifier listed skills that they did not realize they had. P5 was particularly enthusiastic about this. He entered programmer as his target job, and had worked previously as a programmer. He also worked as a robotics engineer. As he read through the list of skills that were reported for these jobs, he realized that critical thinking was a skill that he had never considered having in the past. Showing job seekers' the list of competencies of their past occupations provided an opportunity for them to learn about the skills they had acquired and think about how these concerned the new positions they were planning to apply to.

5.1.2 Fostered Self-reflection on Career Identity. Interacting with the tool helped seven participants (i.e., P3, P4, P6, P9, P10, P12, and $\mathrm{P} 13$ ) reflect on their employment history, and subsequently on their professional identity (i.e., who they were and where they were going from a career point of view). Incidentally, this was caused by a limitation of the tool: the rigid job titles. The job titles displayed in the tool are retrieved from the $\mathrm{O}^{*} \mathrm{NET}$ database and 
follow a somewhat standardized definition. However, the same job title might be spelled in seemingly different forms depending on the industry, or be connected with different practices in different geographical regions. As a consequence, several participants could not find exact matches for the occupations and were obliged to think about alternative ways to describe their previous or target works. This prompted reflection on the job families their past employments belonged to, i.e. the root description of the function of the job, and around alternative descriptions with which this function might be referred to.

For instance, P10 worked as a saleswoman in the retail sector, but was looking for a back office position in retail (e.g., warehouse provisioning). She input 'stock' in SkillsIdentifier and received four suggestions, none of which she was quite looking for (see Figure 6): "I am not sure what to pick. I feel I cannot select 'manager' as I do not have the necessary background. The inventory clerk is still too much involved with the shops and I am looking more for a... desk job! Perhaps, I need to discuss more with my counselor." [P10] This exercise made the participant realize that she had not been clear about what kind of job she wanted to eventually get. After the initial interview, she scheduled a meeting with the ORP counselor and they discussed career options. Eventually, she took an apprenticeship position in the warehouse of a shoe manufacture company to learn about the business. As suggested by this example, some participants had challenges aligning their dream career identity with standardized job titles. This prompted them to reflect on their potential career identities and on how to position themselves in the job market.

5.1.3 Inspiring Career Exploration. Reviewing skills on SkillsIdentifier could encourage job seekers to explore other job opportunities. $\mathrm{P} 14$, who recently relocated, and who worked as a teacher's assistant in the past supporting speech-impaired children, provided a vivid example. In her home country this role was described by the generic title "Teacher Assistant" and to get this position, she was not required to take any specific training. However, by using the tool she discovered that in her new country the same job was not an assistant position and it was described with the title "Special Education Teacher" (see Figure 6). She then consulted a few pages on the Internet and she learned that in the new country this job required specific training: "In my own country, I helped the teacher understand what the speech-impaired children were saying by translating the sign language. I would love to find a job like that here as well. However, here I need a diploma of special education to apply to those positions. I started looking at how I could get this additional training to get the certification." [P14] P14's example demonstrated that job seekers need external inspiration to foster their career exploration. Our three-week deployment allowed participants to integrate SkillsIdentifier to their job search practice, and they had opportunities to explore career choices and information after using the tool.

For instance, P13 who could not immediately find a position in IT commented that the tool could help him find temporary positions while a target position becomes available: "Ultimately, I want to get a position in IT, but while I find what I really want, I need to survive! Perhaps one of the thing the tool (SkillsIdentifier) can do is to show other types of jobs that we can apply to with the set of skills we already have. That would be super useful!" [P13] Similarly, some participants mentioned that when the users do not possess the required skills for a given position, SkillsIdentifier could show the competencies that would be important to acquire before postulating. For instance P9 worked in the back office of a large company to prepare employee paychecks. He was now interested in applying to an administrative assistant position, and described this missing functionality: "See here I can see a list of skills I already have. However, it does not show the skills that I do not have. I would love to know what I am lacking and perhaps how I can get these skills before I can apply to this type of jobs. That can also help me guess what would be my chances of getting a job interview if I apply without the required set of skills." [P9]

\subsection{Supporting Skill Appropriation and Adaptation}

The participants who added skills generated by SkillsIdentifier to their resume all shared a common sentiment that the competencies listed by the tool were useful to describe their abilities and the fit with their target occupations. For this reason, they chose to add some of the skills identified by the tool to their resume. For instance, P4 an immigrant in her 30s, with a background as administrative assistant and receptionist, and who sought a position as police officer, mentioned that the tool helped clarify commonalities between her past roles and her target occupation: "These two jobs have lots in common [referring to admin. assistant and police officer, ed.]. I took time management from the list because this is something I had not thought of before" [P4] As demonstrated in the above example, when participants were adding competencies to their resume (or cover letter), they were selective. They did this for multiple reasons, which are detailed in the next subsections (cf. Subsec. 5.1 and Subsec. 5.4).

However, several participants mentioned difficulties in making use of the output provided by the tool. The problems they reported were not so much in understanding the list of skills per se, but rather in understanding how these could be meaningfully presented in their resume. While some participants used templates that already included sections for listing soft skills, many others did not know where nor how to include these in their curriculum. Figure 5 shows examples of resumes we saw in use during the deployment. For instance, P16 did not have a section of his resume where he could easily type the skills displayed by SkillsIdentifier. During the exit interview he explained: "Honestly, I did not know where to put this list of skills. Currently my resume is organized by previous occupations. For each occupation I have added my main responsibilities. These skills are rather general ... I was not sure where these might go." [P16] As this quote suggests, the current tool did not support all users in understanding how to personalize the suggestions in the context of the previous occupations and how to present visually the competencies in the resume. On the other hand, for other users this adaptation was almost seamless. For instance P3 showed a new version of her resume during her final interview. She had added a new skill learned on SkillsIdentifier: active listening. The template of her resume had a section to list competencies right at the top, and she used that space to list the newly learned skill (see Figure 5, right).

In general, while we saw interesting examples of use of the skills learned via the tool during the three-week deployment, we also noticed that several participants could have been better supported 

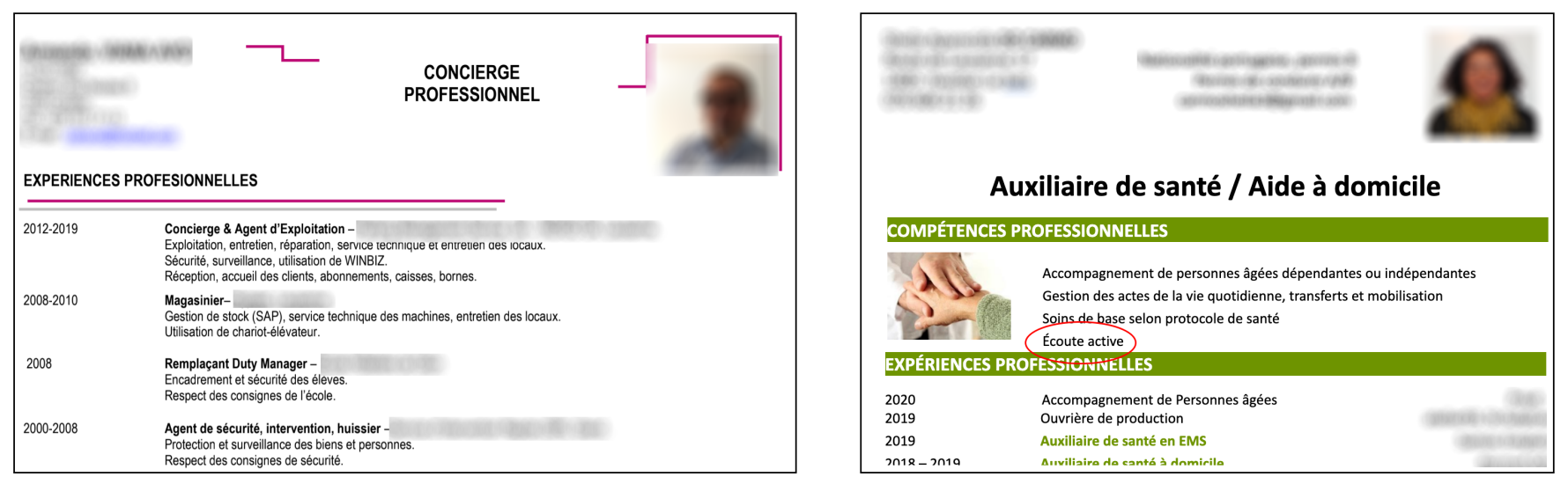

Figure 5: Left: P16's resume did not list skills; Right: P3's resume had space for listing soft skills at the top of the document. The circled red skill (i.e., Écoute active, or active listening) was added during the deployment.

if the tool provided more guidance on how to use the list of skills in their whole job search process (and specifically on how to present these skills onto their resume, or cover letter). In addition to these points, the study helped reveal several opportunities and limitations of the current design of the tool, which we describe next.

\subsection{Supporting Vocabularies and Structure for Job Seekers in Need}

Most of the immigrant participants in the study (P2, P3, P7, P10, P12, P13, and P16) commented positively about the tool's ability to support users whose mother tongue was not French, the national language spoken in the region where they were looking for jobs. Precisely expressing competencies in the resume, requires a technical vocabulary that immigrant job seekers might not possess in the first stages of life in the new country. SkillsIdentifier makes the relevant terms visible and available to the job seekers. For instance, P13 an immigrant from Iran who had a technical background but who could not immediately find a position in IT and had to fall back to a retail position, commented on the utility of the system: "I used the tool to update in French my list of skills. French is not my mother tongue and it is useful to know how to express certain concepts. For instance, I did not know how to write service orientation." [P13]

Other participants saw the benefit of the tool in that it helped them communicate their past experience in a professional manner. Many of these participants expressed the lack of meta-cognitive skills required to describe the competencies typically implied in their prior occupations: a gap typically described as "doing the job" vs. "describing what it takes to do the job". For instance, P12 who was working as a cleaner and as a nanny, but looking for a position as an assistant nurse, explained: "There are things I do everyday for which I don't have a diploma, but I have a lot of experience. This tool is useful because I don't have a structured way to talk about my qualifications and the tool can help me list what is worth mentioning in my resume." [P12] While for some users the appropriation of the output of the tool was immediate, for others the tool did not provide enough information to understand how to work with basic skills. We will discuss this point next.

\subsection{Missing Context for Basic Skills}

During the exit interviews seven participants (i.e., P1, P3, P5, P8, $\mathrm{P} 12$, P13, and P16) mentioned that the most basic skills listed by the tool were too generic and that these would require additional explanation. SkillsIdentifier relied on the list of skills stored in the $\mathrm{O}^{*} \mathrm{NET}$ database. As detailed in section $3, \mathrm{O}^{*} \mathrm{NET}$ contains a list of 35 distinct skills that are organized in 6 groups: Basic Skills, Complex Problem Solving Skills, Resource Management Skills, Social Skills, Systems Skills, and Technical Skills. The basic skills include competencies such as: reading and writing. In many cases these skills were the most common denominator between the previous and target occupations and were listed by SkillsIdentifier in the list of overlapping skills. However, participants felt that these were part of the basic competencies each worker would need to possess to do any kind of job, and that listing them explicitly in their CV might not come across as professional. For instance, P1 who was currently working as an administrative assistant, but looking for a new position as a HR assistant, described how the basic skills would need to be further explained in the situation of her previous jobs: "Some of the skills are a bit too obvious. The description is shallow. For instance writing is something everyone should be able to do. Given I am an administrative assistant, I would use something like text editing, or typing. For other skills it is unclear what aspect is being highlighted. For instance for speaking, I would use communication ability." [P1] As this quote suggests, the current design of the tool lacked detail on what possessing a skill means in the context of a specific occupation, how this was beneficial for the role, and how this was related to the profession (e.g, writing becomes typing in the administrative domain). In addition to this limitation, another point of concern that emerged from the study was the distinction between technical and interpersonal competencies, as we will discuss next.

\subsection{Lack of Guidance to Demonstrate Soft Skills}

Nine participants (i.e., P2, P3, P4, P9, P10, P11, P13, P14, and P15) noticed that the listed skills were personal in nature, or soft skills. They concerned competencies that were interpersonal (how one handles interactions with others) and intra-personal (one's ability 
P10 Entrez jusqu'à 4 emplois précédents:

Vendeurs au détail

Venders au detal

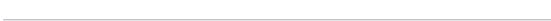

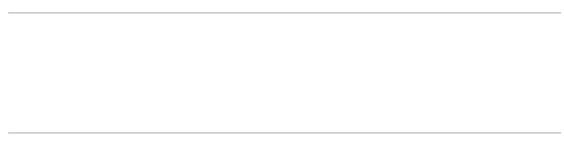

À quel poste souhaitez-vous postuler?

stock

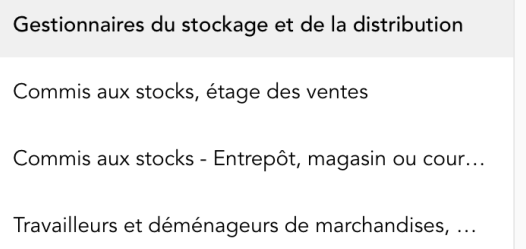

P14 Entrez jusqu'à 4 emplois précédents:

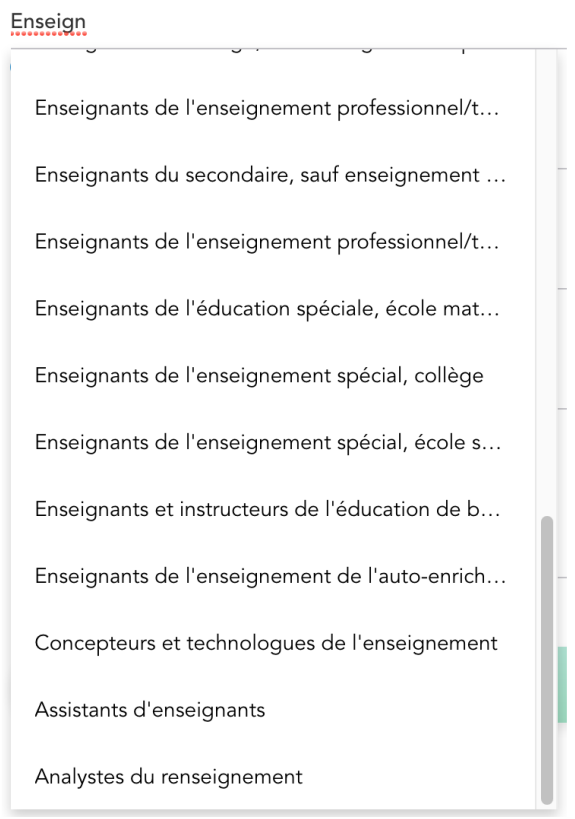

Figure 6: Left: P10 was confused on which target job to pick given her previous employment history; Right: P14 realized by looking at the options provided by the tool that in the new country there were no teaching assistant positions for special education. The headers in this screenshot read: "Please list up to four jobs" and "What jobs would you like to apply for".

to manage oneself) [33]. Hard skills, are typically skills that are more technical in nature (e.g., working with equipment) [33]. Some literature describes hard skills as "learnable" skills where soft skills are more difficult to teach and thus, learn. A majority of the listed skills in the study were related to inter-personal communication skills or high-level problem-solving skills, such as active listening, public speaking, and reading comprehension. Several participants felt these skills were more relevant in a resume than technical skills. While hard skills could be inferred or easily derived from previous employments or education, soft skills are not simple to formalize and are as important than technical knowledge. P2 was an immigrant from Poland in his 20s. He was in training but looking for part-time positions to pay for his studies and felt that listing soft skills was harder than listing hard skills: "I have the feeling there are more soft skills than hard skills in this list. For me it is great because I think it is easy to list the hard skills, while I have a harder time defining my soft skills." [P2] Similarly, P9 mentioned: "Soft skills are very important to mention during the interviews. We don't always think about putting them in our resumes and the app helps figure them out." [P9] When we asked why he thought soft skills were not important to indicate on resumes he added: "Not sure ...I always thought resumes should focus on technical core competencies. I think recruiters choose for what we can do more than for who we are." [P9] This quote highlights a common misconception that many job seekers might share that soft skills are secondary to hard skills when it comes to communicating one's ability to perform well in a given job. Several participants reported how soft skills were often communicated in the interviews, especially in the offline face-toface environment. Past research has shown that employers judge low-wage job seekers' soft skills like job readiness and commitment through non-verbal and indirect signals when recruiting job seekers on social media [35]. This leads to a key question about how individuals can demonstrate the necessary soft skills they possess to employers, when communication channels are limited in the post-COVID job market.

In addition to this positive feedback, several participants mentioned the desire to have a more diversified palette of skills provided by the tool. For instance, P4, a returning immigrant from Portugal in her 30s, mentioned that the soft skills provided by the tool could be complemented by other types of competencies to have an even more complete description of her abilities: "Hard to say what is more important to highlight, it depends on the recruiter. For some it could be work styles ... for others it could be more technical abilities. It would be great if this tool would provide a more comprehensive list so that we can ... pick and choose!" [P4] In this case, $\mathrm{P} 4$ questioned the effectiveness of identifying skills in the job search process by attributing it to the broader knowledge and informational asymmetry between job seekers and employers. For example, job seekers often did not have a clear understanding on what exact skills employers were looking for in specific positions, whether including specific skills in the resumes would help them attract employers, and how employers would evaluate specific skills they possessed. 
Next, we discuss our results in the larger body of research we have previously introduced and we provide perspective on how the design of SkillsIdentifier could evolve.

\section{DISCUSSION}

We discuss the results of a three-week deployment to answer the following two research questions: 1) How do underrepresented job seekers, in a Swiss-based context, integrate SkillsIdentifier into their long-term job-seeking practices? and 2) How can SkillsIdentifier be improved to support the needs of job seekers more broadly (e.g., outside of the U.S.)? Our long-term field deployment confirms a past U.S.-based study of SkillsIdentifier [17], which was evaluated in a single instance. Similar to this study, we found that SkillsIdentifer was useful for job seekers to identify skills to include in their job search materials. Themes emerging from our data mirrored the prior work's findings, which show how the prior findings extended to a longer-term deployment. Our results show how job seekers utilized SkillsIdentifier for job search preparation and were inspired to look for information beyond their current job search. In our Swissbased context, SkillsIdentifier was especially helpful for immigrant participants with limited knowledge of the local technical vocabulary and to job seekers with lower educational backgrounds. Job seekers were inspired to reflect on their career identity and explore job choices they did not think of. To improve SkillsIdentifier, we found that job seekers needed to have more context to articulate the listed skills, guidance about how and where to adapt the skills on their CVs, and information of skills that they did not possess but were needed to perform their target occupations. Our longitudinal deployment also surfaced new opportunities for SkillsIdentifier to support job seekers' effort in filling their skill gaps. Therefore, we discuss concrete ways to redesign SkillsIdentifier based on the findings of our longitudinal deployment. Thereafter, we situate our work in past literature in the fields of human-computer interaction and adjacent fields to reflect on the power asymmetry experienced by job seekers in the job search. We reflect on the unintended consequences that might occur as a result of emphasizing skills in a post-COVID labor market.

\subsection{Articulating Current Skills and Identifying Missing Skills}

Our results show how the identification of skills could be beneficial to job seekers directly (i.e., by improving their job search materials) and indirectly (i.e., by inspiring self-reflection on career identity and exploration). While our participants used SkillsIdentifier to enrich their job search materials, we found that the presentation of "skills" alone was not sufficient. Details embedded into unique job contexts are critical and are often missed when focusing on single skills. In other words, a single skill could have a much larger and broader scope and might insufficiently highlight a job seeker's ability or value. In fact, past literature suggests that the ability to articulate skills to adapt to different job domains is critical for employment in today's fast-shifting job market [45] and seen in Switzerland, a country experiencing industrial transformation. Our results suggest that while job seekers benefited from SkillsIdentifier, it was necessary for the tool to take such context into account. In addition to articulating their skills, job seekers must identify missing skills required to land the jobs they were aiming to land. In fact, past research suggests that tools providing training and education for skills can increase the opportunities of employment [11]. However, job seekers with less than a college degree may not have access to or knowledge of the skills needed to land the jobs they desired, which poses another barrier for employment. Keeping this in mind, we suggest that similar job tools provide specific examples of how to present skills, provide additional job context in case they vary across regions and job titles, present information beyond skills, and finally, provide direction for job seekers to obtain the skills needed to land their desired positions. We apply these recommendations and reimagine how SkillsIdentifier might better support underrepresented job seekers' going forward (see Figure 7 and 8$).{ }^{13}$

6.1.1 Providing additional information on occupations and on skills. Tools that highlight job seekers' skills should take different occupations' contexts into accounts and provide context-specific details. These context-specific details are critical given that the current labor markets shift fast with the impact of artificial intelligence labors and industrial transformation [14]. A tool that helps job seekers articulate their skills with enough context-specific details would support job seekers in overcoming labor market shifts. In the redesigned version of SkillsIdentifier, we imagined this feature to surface on two points of the interaction: during the input of the occupations, and during the inspection of the suggested skills. Concerning the former, we can imagine that when the user is looking for past or target occupations, the tool would display a tooltip with additional information on occupations, to understand naming conventions and responsibilities of the job (see Figure 7b). Concerning the latter, when the tool displays the list of skills, a tooltip can be used again to provide a definition for the given item in the list (see Figure $8 b$ ).

6.1.2 In addition to skills, present work styles, knowledge and abilities. The study revealed that participants wished the tool could provide additional information that could help describe fit with the target occupation. In fact, this information indeed exists in the original $\mathrm{O}^{*} \mathrm{NET}$ database [49], although it was not shown to our participants. In addition to skills, the $\mathrm{O}^{*} \mathrm{NET}$ information contains: work styles, or the personal characteristics that can affect how well an individual might perform in a job; abilities, or means that influence the acquisition and application of knowledge in problem solving; and knowledge, or organized sets of principles and facts applying in general domains that are going to be needed in a given job. In the revised SkillsIdentifier, we added a dashboard that presents a report of competencies based on prior and target jobs (see Figure 7a). The competencies are organized in the top four categories provided by $\mathrm{O}^{*} \mathrm{NET}$. Each category is color coded. The user can then visualize the list of acquired competencies by category or by occupation by selecting “Journey” (see Figure 8b). In this page, past and target occupations are displayed in a timeline and the key competencies for each occupation are listed below the occupation title. Competencies of a given category are visualized

\footnotetext{
${ }^{13}$ High-resolution versions of the mocks presented in this section are available at https://osf.io/5xs6t/.
} 


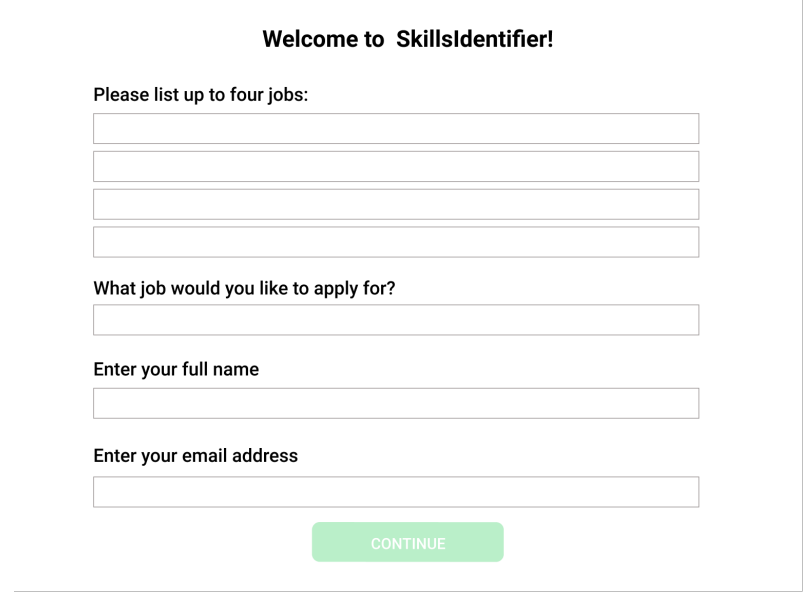

(a)

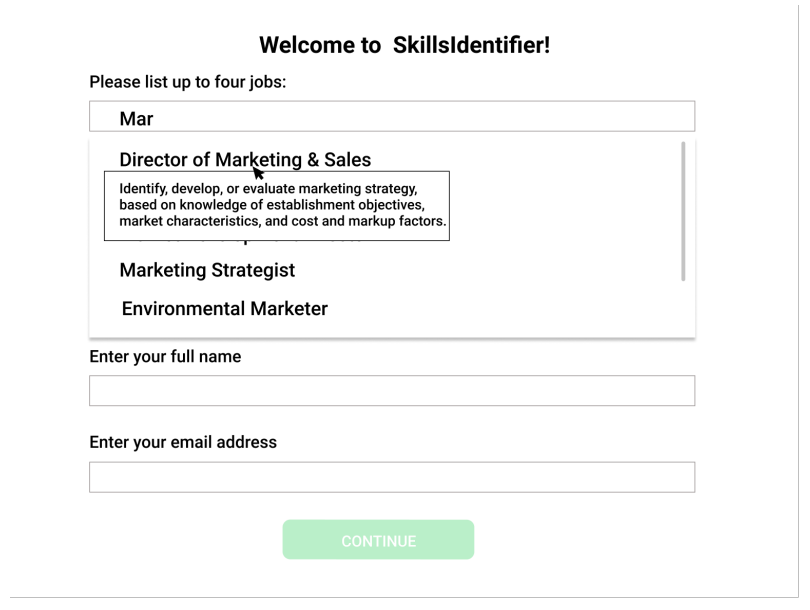

(b)

Figure 7: Redesigned SkillsIdentifier to better provide job information and detail: (a) In addition to past and target occupations, the tool collects name and email to customize the resume; (b) In addition to preemptively suggesting occupation titles, the tool presents a tooltip overlay with definitions for each occupation.

using a tag design and the tags are color coded following the same schema of the top categories.

6.1.3 Besides skills that overlap, present skills that require further development, and provide options on how to acquire those. A tool should provide information regarding a job seeker's missing skills for their target jobs. While SkillsIdenfier served well to inform job seekers about their skills, it does not provide skills that job seekers need to develop for their target jobs. In fact, this need was addressed by another tool DreamGigs, which was developed by Dillahunt and Lu [20]. DreamGigs allowed job seekers to enter the "dream job" they want to apply for, and it output skills and training required to reach the job. Our results suggest that an employment tool that supports job seekers' skill development should combine these two tools' features. In other words, a tool should help job seekers identify their current skills and help navigate ways to fill missing skills for their target jobs. In the revised SkillsIdentifier, we supported this exploration by showing skills which require further development to improve fit with the target job (see Figure 8b). In addition, users can explore ways to acquire the missing skills by means of courses, volunteer opportunities or intermediary jobs (see Figure 8d).

6.1.4 Providing examples on how to present skills in a resume. The study also revealed that job seekers sometimes may struggle to understand how to best present their competencies and fit to a given position in their application materials. Therefore a tool that aims to support job seekers during their unemployment spell should not only provide concrete elements to evaluate fit with regard to the target job, but also provide examples on how to communicate this fit to recruiters. In the revision, we show a resume template that is pre-populated with the information collected during previous steps of the interaction (see Figure 8c). Here, the user can visualize past occupations and see related competencies. The tool also allows the user to edit the content of the resume if needed and download it for further adaptation.

\subsection{Implications for Post-COVID Labor Market}

Moving beyond the above design recommendations, our findings embody and reveal several broader challenges faced by underrepresented job seekers within the current labor market structure. In this section, we unpack and situate these challenges in prior work; we discuss their potential implications on the already precarious labor market, especially amid the Covid-19 pandemic.

In the context of contemporary labor market and advancement of technologies, Gershon reminds us that modern job seekers are viewed as "bundles of skills" that can fulfill an organization's operations and interests [24]. Employers have been breaking their needs into specific skills, which they match with those skills presented by job seekers. In this way, aspects of an individual's personality and social interactions (such as communication, listening, writing, and being flexible) become transferable soft skills that contribute to either productivity or profit. This serves as a form of skills tokenization (i.e., breaking the needs of a company into specific skills) and allows industries to quantify and measure an individual's value [51]. Corporations for instance exemplify soft skills as the key to a successful business and to an individuals' career success [24]. One could consider soft skills in a way as "technologies of self" [23]. Soft skills allow job seekers to shape how they should view and present themselves so that they align with the ever-shifting conditions of the labor market. As Urciuoli puts it, evaluating job seekers as bundles of skills and emphasizing soft skills privileges an employer's interpretation and assessment over a job seekers' everyday realities [51].

In our study, participants were aware that they were being assessed by employers based on how they presented their skillshelping them articulate their skills was indeed the purpose of the 

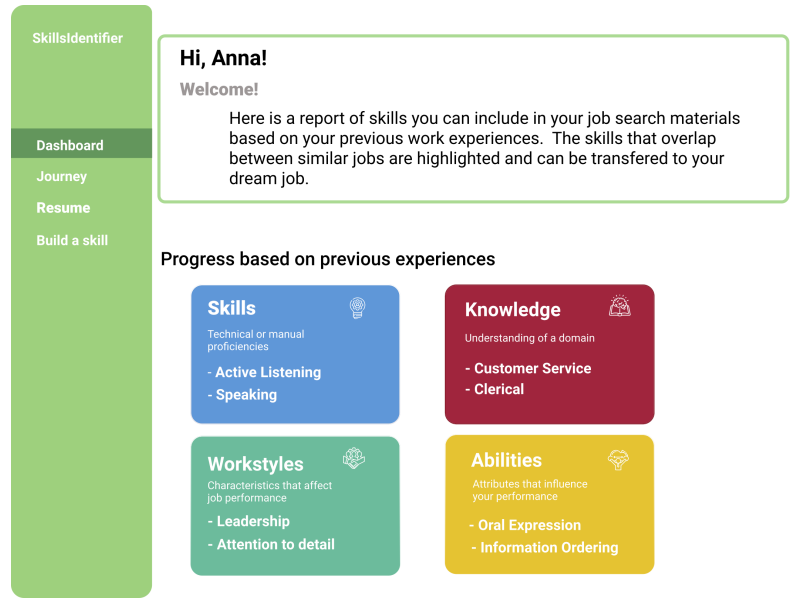

Progress based on previous experiences
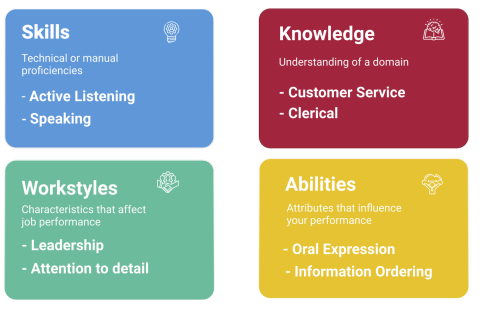

(a)
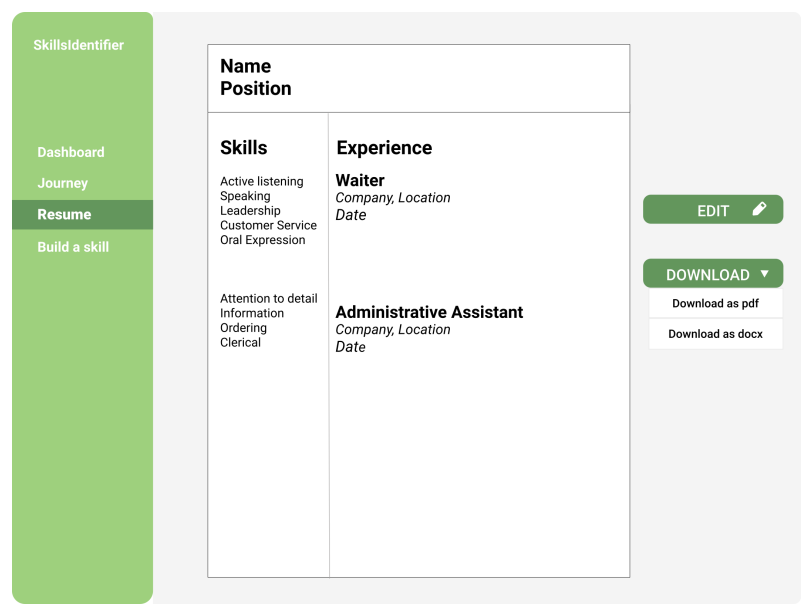

(c)
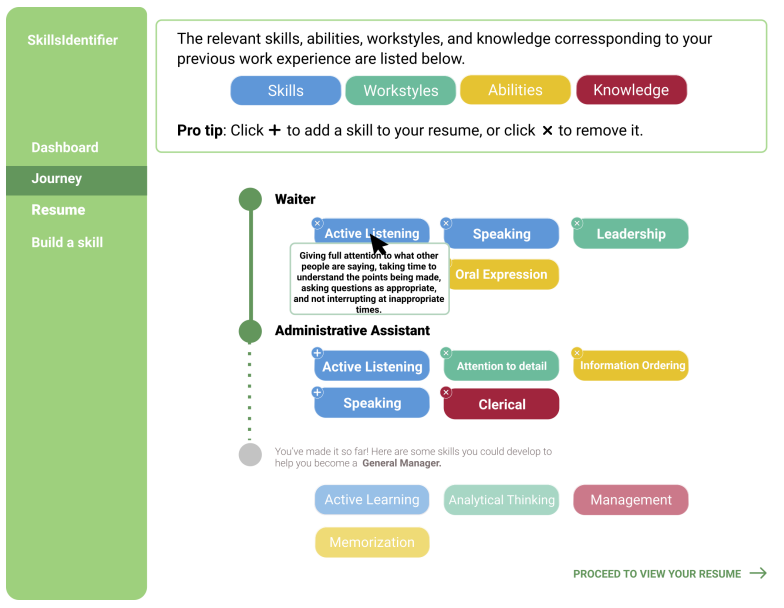

(b)
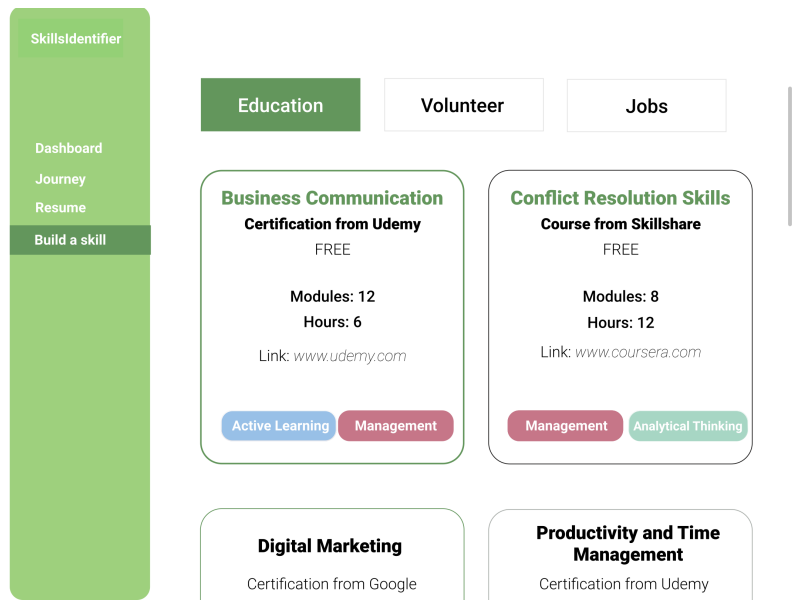

(d)

Figure 8: Redesigned SkillsIdentifier: (a) Dashboard showing competencies that overlap between past and target occupations; (b) User journey that displays the competencies that overlap by past occupation and the missing competencies; (c) Resume template, here again competencies that overlap are organized by past occupations; (d) Opportunities for acquiring missing competencies.

tool. Participants analyzed the skills they might have possessed in an attempt to fit them to what employers might value. We frequently saw throughout our study how job seekers were not always sure what employers were looking for in the application process and that it varied from employer to employer. Recall from P4: "hard to say what [skill] is more important to highlight, it depends on the recruiter." Similarly, P9 stressed that recruiters tended to choose candidates based on their ability to facilitate organizational interests but overlook job seekers' true selves. Such findings highlight employers' power to determine what their "ideal" job candidates should look like and what their "bundles of skills" should consist of [24]. Such power is often engineered into the recruitment and hiring process and invisible to job seekers. As such, our results suggest salient knowledge and power asymmetry between job seekers and employers in the "self-as-business" paradigm [51]. In other words, job seekers have limited control over what skills they should present, what skills are valued by recruiters and employers, and how their presented skills are perceived by employers. This knowledge and power asymmetry mirrors the power imbalance identified in a recent HCI work on investigating employers' socio-technical practices of using social media in recruiting low-wage workers [35].

Further, the process of forcing job seekers to specify their value into a single unit risks decontextualizing their lived experiences and situated knowledge. Recall that P1 believed the identified skill of "writing" could not accurately reflect their current work as an administrative assistant. Some participants were able to internalize and make sense of the identified skills through their past experience and tools like SkillsIdentifier provide job seekers with a better description of the skills identified. However, we question how the loss of context impact employers' subjective evaluation and scrutiny on 
job seekers. This issue is especially critical when job application and recruitment have become increasingly computer-mediated. Before the pandemic, job seekers could convey their qualifications through face-to-face interactions; however, the social-distancing requirements severely limits such interactions. In the online environment, employers and recruiters tend to use non-verbal cues as proxies to assess job seekers based on their own interpretation, which are often inaccurate due to the lack of context [35]. Furthermore, immigrant workers in our study underscored that skills were often culturally-specific. Our interviews revealed that new immigrants did not necessarily know the appropriate way to translate and present their skills and experience gained outside of Switzerland. These findings lead to further questions of how we should better support job seekers' presentation of selves beyond identifying skills. Allan's recent work problematized the trend of emphasizing and measuring the soft skills of new immigrants in Canada and highlights how this process could perpetuate discrimination against immigrant workers [2]. In the Swiss context, immigrant workers similarly experience challenges in participating in the labor market as a result of the systematic discrimination along the lines of class, gender, and ethnicity [42]. Our findings highlight the potential of how quantifying and evaluating skills could amplify the power asymmetry between immigrant job seekers and employers. As Allan puts it, "hierarchies between immigrants and the native-born are reinforced and reified as new immigrants are compelled to conform to [local] ways of being and speaking, for sociocultural difference is construed as a 'skills deficit' "[2, p.637]. While it is beyond the scope of this current paper, it is critical for future HCI researchers and practitioners to reflect upon the intended and unintended social, cultural, and political impacts on immigrant and underrepresented job seekers when designing for upskilling and reskilling.

\subsection{Ethical Considerations and Future Research}

Taking this further, with the rise of data-driven hiring technologies, tokenizing job seekers into bundles of skills makes room for algorithmic systems to exacerbate the power imbalance between job seekers and employers. For example, Quantified Communications ${ }^{14}$ recently developed an AI-powered platform that aims to "accurately" and "objectively" measure individuals' soft skills including items like trustworthiness, facial expressions, use of pauses in the communication, and more:

Let's consider the most foundational soft skill: communication. Innovations in technologies like natural language processing, vocal recognition, and facial analysis mean that, today, machines can assess a professional's predicted impact on her audience [emphasis added]-how trustworthy others will find her, or how inclusive, open-minded, or confident-identifying not only whether she possesses the communication skills the company is looking for, but whether her communication style indicates that she'll be a good cultural and behavioral [emphasis added] fit for the organization $\mathrm{CEO}$ and Co-Founder of Quantified Communications [54]

\footnotetext{
${ }^{14}$ See https://www.quantifiedcommunications.com/, last retrieved February 2021.
}

Past research has cautioned us against many technologies mentioned in this claim-including natural language processing, vocal recognition, and facial analysis. Such technologies have and continue to perpetuate inequalities based on gender, race and ethnicity, nationality, (dis)ability, and more [3]. Past HCI studies have also shown evidence of how algorithmic hiring technologies could disadvantage and scrutinize job seekers based on race and ethnicity [55] and gender [10]. Tying it back to our results that soft skills are often culturally defined and specific, we speculate that data-driven evaluations on whether a job seeker is a "good cultural or behavioral fit for the organization" through quantifying one's human traits as soft skills could become a rhetorical device for obscuring discrimination in the labor market. We argue that such data-driven evaluations on one's soft skills could actually embody and uphold the same power asymmetry that is inherent to the labor market. Future research and analysis should critically unpack the contingency on and politics of the quantification and measurement of soft skills and make visible the seemingly "invisible" discrimination against underrepresented job seekers.

\section{CONCLUSION}

SkillsIdentifier is a digital intervention designed to assist job seekers identifying and articulating their skill sets in the job search process. Results from our three-week deployment suggest that SkillsIdentifer was useful for job seekers to identify skills to include in their job search materials and was especially helpful for immigrants who were unfamiliar with the local technical vocabularies and job seekers with lower educational backgrounds. Our work confirms a past study of SkillsIdentifier conducted in the United States for a single period. As found in the original study, participant job seekers were inspired to reflect on their career identity and explore job choices they did not think of. However, our results extend this literature and contribute new design implications for this tool. To improve SkillsIdentifier, we found that job seekers required additional context to articulate the listed skills, guidance about how and where to adapt the skills on their CVs, and information of skills that they did not possess but were needed by their target occupations. Our results also raise a number of critical concerns about the emphasis on job seekers' skill sets in the job search process, which could perpetuate the power and knowledge asymmetry between job seekers and employers. With the mitigation to online hiring in the post-Covid labor market and the growing adoption of AI-powered hiring technologies, these concerns are especially critical for future HCI researchers and practitioners to reflect on when designing for upskilling and reskilling going forward.

\section{ACKNOWLEDGMENTS}

We would like to thank Alexandre Senges for his instrumental help conducting the interviews. We thank our participants for their time and insights. This research was funded by the Swiss National Science Foundation (grant n. 178878), the Swiss National Centre of Competence in Research 'Lives' (IP204), and the National Science Foundation (award IIS-1717186).

\section{REFERENCES}

[1] Md Abdullah-Al-Mamun. 2012. The soft skills education for the vocational graduate: Value as work readiness skills. Fournal of Education, Society and Behavioural 
Science 4, 2 (2012), 326-338.

[2] Kori Allan. 2016. Going beyond language: Soft skill-ing cultural difference and immigrant integration in Toronto, Canada. Multilingua 35, 6 (2016), 617-647.

[3] Ruha Benjamin. 2019. Race after technology: Abolitionist tools for the new jim code. Social Forces 98, 4 (2019), 1-3.

[4] George J Borjas and Hugh Cassidy. 2020. The adverse effect of the covid-19 labor market shock on immigrant employment. Technical Report. National Bureau of Economic Research.

[5] Helen Buchs and Marlis Buchmann. 2017. Job Vacancies and Unemployment in Switzerland 2006-2014: Labor Market Mismatch and the Significance of Labor Market Tightness for Unemployment Duration. Technical Report. SECO Publikation, Bern, Switzerland. 55 pages.

[6] Bureau of Labor Statistics 2018 (accessed March 15, 2019). Labor force char acteristics by race and ethnicity, 2017. Bureau of Labor Statistics. https //www.bls.gov/opub/reports/race-and-ethnicity/2017/home.htm

[7] Bureau of Labor Statistics 2018 (accessed March 15, 2019). Labor Force Statistics from the Current Population Survey. Bureau of Labor Statistics. https://www.bls. gov/web/empsit/cpseea10.htm

[8] Bureau of Labor Statistics 2018 (accessed March 15, 2019). Unemployment rates and earnings by educational attainment. Bureau of Labor Statistics. https: //www.bls.gov/emp/chart-unemployment-earnings-education.htm

[9] Bureau of Labor Statistics 2018 (accessed March 27, 2019). Economic News Release: Persons with a Disability: Labor Force Characteristics Summary. Bureau of Labor Statistics. https://www.bls.gov/news.release/disabl.nro.htm

[10] Le Chen, Ruijun Ma, Anikó Hannák, and Christo Wilson. 2018. Investigating the impact of gender on rank in resume search engines. In Proceedings of the 2018 CHI conference on human factors in computing systems. ACM, New York, NY, $1-14$.

[11] Su Jung Choi, Jin Chul Jeong, and Seoung Nam Kim. 2019. Impact of vocational education and training on adult skills and employment: An applied multilevel analysis. International fournal of Educational Development 66 (2019), 129-138. https://doi.org/10.1016/j.ijedudev.2018.09.007

[12] European Commission. 2020. European skill accreditation system. https: //cordis.europa.eu/article/id/6896-european-skill-accreditation-system

[13] Seth Deepa and Manisha Seth. 2013. Do soft skills matter?-Implications for educators based on recruiters' perspective. IUP Journal of Soft Skills 7, 1 (2013), 7.

[14] Robert J DeFillippi and Michael B Arthur. 1994. The Boundaryless career: A Competency-based Perspective. fournal of Organizational Behavior 15, 4 (1994) 307-324. https://doi.org/10.1002/job.4030150403

[15] Jonas Deplazes. 2019. Labour market indicators for 2019. Technical Report. Federal Statistical Office (FSO), Neuchatel, Switzerland. 16 pages. https://www.bfs.admin $\mathrm{ch} /$ bfsstatic/dam/assets/9386090/master

[16] Tawanna R. Dillahunt, Nishan Bose, Suleman Diwan, and Asha Chen-Phang. 2016. Designing for Disadvantaged Job Seekers: Insights from Early Investigations. In Proceedings of the 2016 ACM Conference on Designing Interactive Systems (Brisbane, QLD, Australia) (DIS '16). ACM, New York, NY, USA, 905-910. https://doi.org/ $10.1145 / 2901790.2901865$

[17] Tawanna R. Dillahunt and Chiao-Yin Hsiao. 2020. SkillsIdentifier: A Tool to Promote Career Identity and Self-efficacy Among Underrepresented Job Seekers In Proceedings of the 54th Hawaii International Conference on System Sciences. Hawaii International Conference on System Sciences, Honolulu, HI, USA, 4848.

[18] Tawanna R. Dillahunt, Vaishnav Kameswaran, Desiree McLain, Minnie Lester, De lores Orr, and Kentaro Toyama. 2018. Entrepreneurship and the Socio-Technical Chasm in a Lean Economy. In Proceedings of the 2018 CHI Conference on Human Factors in Computing Systems (Montreal QC, Canada) (CHI '18). ACM, New York, NY, USA, Article 240, 14 pages. https://doi.org/10.1145/3173574.3173814

[19] Tawanna R. Dillahunt, Jason Lam, Alex Lu, and Earnest Wheeler. 2018. Designing Future Employment Applications for Underserved Job Seekers: A Speed Dating Study. In Proceedings of the 2018 Designing Interactive Systems Conference (Hong Kong, China) (DIS '18). ACM, New York, NY, USA, 33-44. https://doi.org/10. 1145/3196709.3196770

[20] Tawanna R. Dillahunt and Alex Lu. 2019. DreamGigs: Designing a Tool to Empower Low-Resource Job Seekers. In Proceedings of the 2019 CHI Conference on Human Factors in Computing Systems (Glasgow, Scotland Uk) (CHI '19). ACM, New York, NY, USA, Article 578, 14 pages. https://doi.org/10.1145/3290605.3300808

[21] Tawanna R. Dillahunt and Amelia R. Malone. 2015. The Promise of the Sharing Economy Among Disadvantaged Communities. In Proc. of the 33rd Annual ACM Conference on Human Factors in Computing Systems (Seoul, Republic of Korea) (CHI '15). ACM, New York, NY, USA, 2285-2294. https://doi.org/10.1145/2702123. 2702189

[22] Lynn Dombrowski, Adriana Alvarado Garcia, and Jessica Despard. 2017. LowWage Precarious Workers' Sociotechnical Practices Working Towards Addressing Wage Theft. In Proceedings of the 2017 CHI Conference on Human Factors in Computing Systems (Denver, Colorado, USA) (CHI '17). ACM, New York, NY, USA, 4585-4598. https://doi.org/10.1145/3025453.3025633

[23] Michel Foucault. 1988. Technologies of the self: A seminar with Michel Foucault. University of Massachusetts Press, Amherst, MA.
[24] Ilana Gershon. 2017. Down and out in the new economy: How people find (or don't find) work today. University of Chicago Press, Chicago, IL.

[25] Irena Grugulis and Steven Vincent. 2009. Whose skill is it anyway? 'soft'skills and polarization. Work, employment and society 23, 4 (2009), 597-615.

[26] Gillian R. Hayes, V. Erick Custodio, Oliver L. Haimson, Kathy Nguyen, Kathryn E. Ringland, Rachel Rose Ulgado, Aaron Waterhouse, and Rachel Weiner. 2015. Mobile video modeling for employment interviews for individuals with autism. Journal of Vocational Rehabilitation 43, 3 (2015), 275-287.

[27] David G. Hendry, Norah Abokhodair, Rose Paquet Kinsley, and Jill Palzkill Woelfer. 2017. Homeless Young People, Jobs, and a Future Vision: Community Members' Perceptions of the Job Co-op. In Proceedings of the 8th International Conference on Communities and Technologies (C\&T '17). ACM, New York, NY, USA, 22-31. https://doi.org/10.1145/3083671.3083680

[28] David G. Hendry, Jill Palzkill Woelfer, and Thuy Duong. 2017. U-District Job Co-op: constructing a future vision for homeless young people and employment. Information Technology \& People 30 (2017), 602-628. http://www.emeraldinsight. com/doi/full/10.1108/ITP-05-2015-0117

[29] Julie Hui, Kentaro Toyama, Joyojeet Pal, and Tawanna Dillahunt. 2018. Making a Living My Way: Necessity-driven Entrepreneurship in Resource-constrained Communities. Proc. ACM Hum.-Comput. Interact. 2, CSCW, Article 71 (Nov. 2018), 24 pages. https://doi.org/10.1145/3274340

[30] Michael T Kane. 1990. Identifying and describing the skills required by work. Pelavin Associates, Washington, DC

[31] Jessie Koen, Ute-Christine Klehe, Annelies EM Van Vianen, Jelena Zikic, and Aukje Nauta. 2010. Job-search strategies and reemployment quality: The impact of career adaptability. Fournal of Vocational Behavior 77, 1 (2010), 126-139.

[32] Alexandra Kohler. 2019. Swiss workplace inequality, by the numbers. https://www.swissinfo.ch/eng/mind-the-gap\{_\}inequality-in-the-swissworkplace--by-the-numbers/44809274

[33] Dennis R Laker and Jimmy L Powell. 2011. The differences between hard and soft skills and their relative impact on training transfer. Human Resource Development Quarterly 22, 1 (2011), 111-122.

[34] Alex Lu, Jason Brill, and Tawanna R. Dillahunt. 2018. DreamGigs: A "Stepping Stone" for Low-Resource Job Seekers to Reach Their Ideal Job. In Companion of the 2018 ACM Conference on Computer Supported Cooperative Work and Social Computing (Jersey City, NJ, USA) (CSCW'18). Association for Computing Machinery, New York, NY, USA, 317-320. https://doi.org/10.1145/3272973.3274086

[35] Alex Jiahong Lu and Tawanna R. Dillahunt. To Appear. Uncovering the Promises and Challenges of Social Media Use in the Low-Wage Labor Market: Insights from Employers. In Proceedings of the 2021 CHI Conference on Human Factors in Computing Systems (Yokohama, Japan) (CHI '21). Association for Computing Machinery, New York, NY, USA, 13 pages. https://doi.org/10.1145/3411764. 3445774

[36] Ranjit Singh Malhi. 2009. The hard truth about graduate employability and soft skills. ADEPT: Higher Education Leadership Research Bulletin 3 (2009), 45-56.

[37] A. J. Metz and Janice E Jones. 2013. Ability and Aptitude Assessment in Career Counseling. In Career development and counseling: Putting theory and research to work (2 ed.), Steven D. Brown and Robert W. Lent (Eds.). John Wiley \& Sons, Hoboken, NJ, USA, Chapter 16, 449-476.

[38] Krishna Mishra. 2014. Employability skills that recruiters demand. IUP fournal of Soft Skills 8, 3 (2014), 50.

[39] OECD. 2019. OECD employment outlook 2019: The future of work. OECD Publishing, Paris, France.

[40] Anna Praskova, Peter A Creed, and Michelle Hood. 2015. Career identity and the complex mediating relationships between career preparatory actions and career progress markers. Journal of Vocational Behavior 87 (2015), 145-153.

[41] Noopur Raval and Paul Dourish. 2016. Standing Out from the Crowd: Emotional Labor, Body Labor, and Temporal Labor in Ridesharing. In Proceedings of the 19th ACM Conference on Computer-Supported Cooperative Work \& Social Computing (San Francisco, California, USA) (CSCW'16). ACM, New York, NY, USA, 97-107. https://doi.org/10.1145/2818048.2820026

[42] Yvonne Riaño and Nadia Baghdadi. 2007. Understanding the Labour Market Participation of Skilled Immigrant Women in Switzerland: The Interplay of Class, Ethnicity, and Gender. Fournal of International Migration and Integration / Revue de l'integration et de la migration internationale 8, 2 (2007), 163. https: //doi.org/10.1007/s12134-007-0012-1

[43] Johnny Saldaña. 2015. The Coding Manual for Qualitative Researchers (3 ed.). SAGE Publications Ltd, Newbury Park, CA. 368 pages.

[44] Mark L. Savickas. 2002. Career Construction: A Developmental Theory of Vocational Behaviour. In Career Choice and Development (4 ed.), Duane Brown (Ed.). Jossey-Bass, San Francisco, CA, Chapter 5, 149-205.

[45] Darryn Snell, Victor Gekara, and Krystle Gatt. 2016. Cross-occupational skill transferability: challenges and opportunities in a changing economy. National Center for Vocational Education Research (NCVER). https://www.ncver.edu.au/researchand-statistics/publications/all-publications/cross-occupational-skilltransferability-challenges-and-opportunities-in-a-changing-economy

[46] Joel Spring. 1998. Education and the rise of the global economy. Routledge, England, $\mathrm{UK}$. 
[47] Will Sutherland and Mohammad Hossein Jarrahi. 2017. The Gig Economy and Information Infrastructure: The Case of the Digital Nomad Community. Proc. ACM Hum.-Comput. Interact. 1, CSCW, Article 97 (Dec. 2017), 24 pages. https: //doi.org/10.1145/3134732

[48] Ryo Suzuki, Niloufar Salehi, Michelle S Lam, Juan C Marroquin, and Michael S Bernstein. 2016. Atelier: Repurposing expert crowdsourcing tasks as microinternships. In Proceedings of the 2016 CHI conference on human factors in computing systems. ACM, New York, NY, 2645-2656.

[49] The Department of Labor. n.d.. O*NET OnLine. https://www.onetonline.org/. Accessed 22 January 2020.

[50] Maria Tomprou, Laura Dabbish, Robert E. Kraut, and Fannie Liu. 2019. Career Mentoring in Online Communities: Seeking and Receiving Advice from an Online Community. In Proc. of the 2019 CHI Conference on Human Factors in Computing Systems (Glasgow, Scotland Uk) (CHI '19). ACM, New York, NY, USA, Article 653 12 pages. https://doi.org/10.1145/3290605.3300883

[51] Bonnie Urciuoli. 2008. Skills and selves in the new workplace. American ethnologist 35, 2 (2008), 211-228.
[52] Earnest Wheeler and Tawanna R. Dillahunt. 2018. Navigating the Job Search as a Low-Resourced Job Seeker. In Proceedings of the 36th Annual ACM Conference on Human Factors in Computing Systems (Montreal, QC, Canada) (CHI '18). ACM, New York, NY, USA, 10 pages. https://doi.org/10.1145/3173574.3173622

[53] World Health Organization. 2003. Skills for health: Skills-based health education including life skills: An important component of a child-friendly/health-promoting school. World Health Organization. https://apps.who.int/iris/handle/10665/42818

[54] Noal Zandan. 2020. Soft Skills Are in Demand. Can They Be Measured? https: //www.quantifiedcommunications.com/blog/can-soft-skills-be-measured

[55] Indre Žliobaite and Bart Custers. 2016. Using sensitive personal data may be necessary for avoiding discrimination in data-driven decision models. Artificial Intelligence and Law 24, 2 (2016), 183-201.

[56] Eva Zschirnt. 2020. Evidence of Hiring Discrimination Against the Second Generation: Results from a Correspondence Test in the Swiss Labour Market. fournal of International Migration and Integration 21, 2 (2020), 563-585. https: //doi.org/10.1007/s12134-019-00664-1 